Article

\title{
Synthesis of Ring II/III Fragment of Kanamycin: A New Minimum Structural Motif for Aminoglycoside Recognition
}

\author{
Sandra G. Zárate ${ }^{1,2}{ }^{(}$, Agatha Bastida $^{1}{ }^{1}$, Andrés G. Santana ${ }^{1, *(D)}$ and Julia Revuelta ${ }^{1, *(1)}$ \\ 1 Instituto de Química Orgánica General, CSIC, Juan de la Cierva 3, 28006 Madrid, Spain \\ 2 Facultad de Tecnología, Carrera de Ingeniería Química, Universidad Mayor, Real y Pontificia de San \\ Francisco Xavier de Chuquisaca, Regimiento Campos 180, Casilla 60-B Sucre, Bolivia \\ * Correspondence: andres.g.santana@csic.es (A.G.S.); julia.revuelta@iqog.csic.es (J.R.)
}

Received: 19 June 2019; Accepted: 31 July 2019; Published: 2 August 2019

\begin{abstract}
A novel protocol has been established to prepare the kanamycin ring II/III fragment, which has been validated as a minimum structural motif for the development of new aminoglycosides on the basis of its bactericidal activity even against resistant strains. Furthermore, its ability to act as a AAC- $\left(6^{\prime}\right)$ and APH- $\left(3^{\prime}\right)$ binder, and as a poor substrate for the ravenous ANT- $\left(4^{\prime}\right)$, makes it an excellent candidate for the design of inhibitors of these aminoglycoside modifying enzymes.
\end{abstract}

Keywords: aminoglycoside antibiotics; enzymatic resistance; minimum structural motif; oligosaccharides; pseudo-disaccharide

\section{Introduction}

Since the discovery of streptomycin in 1944 [1], aminoglycosides have found widespread clinical use due to its broad antimicrobial spectrum and rapid bactericidal effects [2,3]. Their mode of action involves binding to the $16 \mathrm{~S}$ ribosomal subunit at the t-RNA acceptor A-site (aminoacyl site), where they interfere with the ability of the ribosome to correctly decode mRNA during protein synthesis [4-7]. Unfortunately, irreversible ototoxic side effects and growing bacterial resistance have narrowed the significance of aminoglycosides as antibiotics in the clinical practice [8].

Kanamycins (1-3) are natural antibiotics belonging to a group of aminoglycosides containing a 4,6-disubstituted 2-deoxystreptamine (ring II) core and have been used against both Gram-(+) and Gram-(-) bacteria for more than fifty-years (Figure 1A) [9]. The pseudo-disaccharide I/II fragments (4-6) of this family of antibiotics, with slightly different $\mathrm{OH} / \mathrm{NH}_{2}$ patterns in unit $\mathrm{I}$, is common to most aminoglycosides and have been considered until now essential for specific complex formation, and consequently, for antibiotic activity (Figure 1B) [10]. For this reason, most approximations to new aminoglycosides described to date involve the synthesis of derivatives maintaining the I/II core and eliminating or modifying ring III [11-13].

Unfortunately, there are many aminoglycoside-modifying enzymes transferring acetyl, phosphoryl and adenyl groups in a cofactor-dependent manner to virtually every amino or hydroxyl substituent of the I/II structural motif (Figure 1A) [14]. As a result, semisynthetic congeners of the 4,6-disubstituted 2-deoxystreptamine class were developed to overcome the inactivating action of a subset of the aforementioned enzymes and their different isoforms prevalent in other pathogens [15-18]. Despite the urgent need of new anti-infective therapies, it should be noted that no new aminoglycoside antibiotic was introduced since the early 1980s [19], up until this year, when promising semisynthetic propylamycin was reported by Crich and coworkers [20]. 
A

$$
\begin{aligned}
1 \mathrm{R}^{1} & =\mathrm{NH}_{2}, \mathrm{R}^{2}=\mathrm{OH} \\
2 \mathrm{R}^{1} & =\mathrm{NH}_{2}, \mathrm{R}^{2}=\mathrm{OH} \\
3 \mathrm{R}^{1} & =\mathrm{R}^{2}=\mathrm{OH}
\end{aligned}
$$
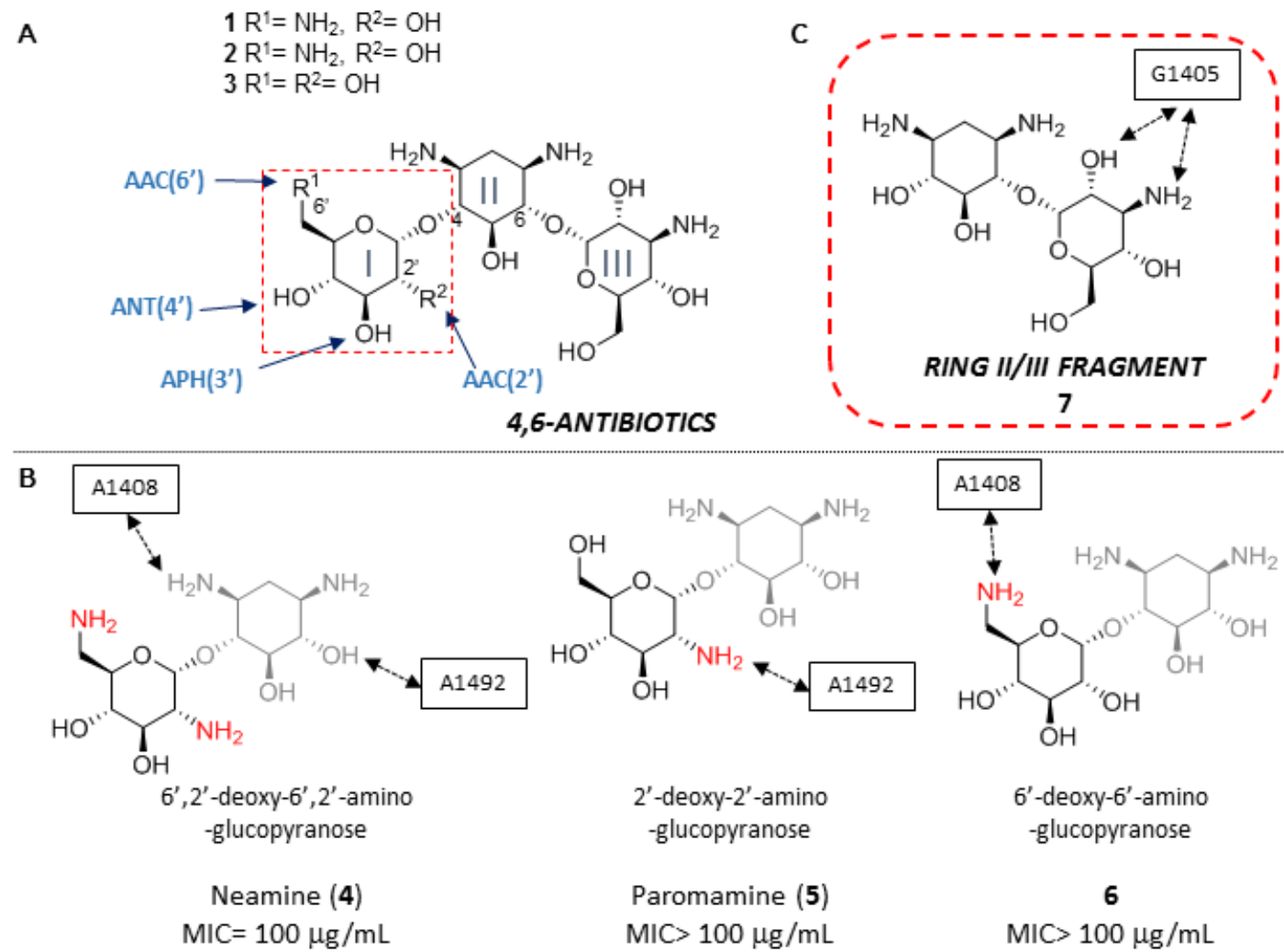

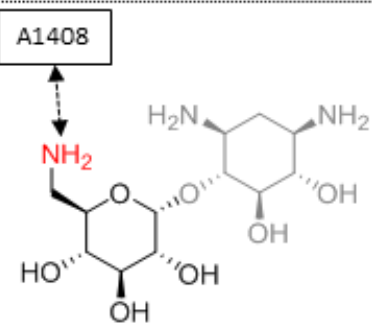

$$
\begin{aligned}
& \text { 2'-deoxy-2'-amino } \\
& \text {-glucopyranose } \\
& \text { Paromamine (5) } \\
& \text { MIC> } 100 \mu \mathrm{g} / \mathrm{mL}
\end{aligned}
$$

$$
\begin{gathered}
6^{\prime} \text {-deoxy-6'-amino } \\
\text {-glucopyranose } \\
6 \\
\text { MIC }>100 \mu \mathrm{g} / \mathrm{mL}
\end{gathered}
$$

Figure 1. (A) Structure of kanamycin A (1), kanamycin B (2) and kanamycin C (3). (B) Ring I/II fragments (4-6) of kanamycins. The functional relevance of the drug/RNA contacts established through ring I amines are indicated in each case. Besides, typical ranges for the MIC values of natural kanamycins (1-3) and of the fragments thereof (4-6) are also presented. (C) Ring II/III fragment studied in this paper (7).

A general way for the discovery of new aminoglycosides can be thus summarized on keeping a minimum structural motif (MSM) that provides basic affinity and, subsequently, hit-to-lead optimization of the resulting structure. Herein, we report on the synthesis of novel pseudo-disaccharide 7 that shows interesting properties as a novel MSM, while still retaining a considerable part of the antibiotic activity against several strains, including some expressing the most clinically relevant aminoglycoside modifying enzymes (Figure 1A).

\section{Results and Discussion}

\subsection{Synthesis of Pseudo-Disaccharide 7}

The preparation of pseudo-disaccharide 7 was carried out according to the sequence described in Scheme 1. Our synthetic effort began with the preparation of tetraazidokanamycin A (8), an intermediate suitably protected with azide groups, according with the procedure described previously by our laboratory [21]. As a next step, simultaneous regioselective protection of C-6" and C-4" hydroxyl groups was achieved by treatment of $\mathbf{8}$ with di-tert-butylsilyl bis(trifluoromethanesulfonate) in pyridine to afford compound 9 in $80 \%$ yield [22]. The protection of C-6" OH was proven to be necessary for minimizing the formation of byproducts and for allowing an easier purification after the regioselective protection of ring I, the key step of our strategy. After undergoing many frustrations attempting the regioselective protection of positions $2^{\prime}$ and $3^{\prime}$ in ring I of kanamycin A [23], we envisioned the use of 2,3-butanodione-bis-dimethyl acetal as a plausible strategy [24]. Indeed, this reaction afforded an equimolar mixture of 10a and 10b, by protection of $C-3^{\prime}$ and $C-4^{\prime}$ hydroxyl groups and C-2' and C-3', respectively, decreasing the total yield of the synthesis considerably given that 10a does not undergo the 
required $\beta$-elimination after periodate oxidation of the remaining diol. Despite this setback, this is to date the best procedure found for the selective protection of 2' and 3' hydroxyl groups of kanamycin A (1). In a next step, Williamson benzylation of the rest of the hydroxyl groups in compound $\mathbf{1 0 b}$ afforded 11 in $65 \%$ yield. Finally, the regioselective deprotection of the $O-2^{\prime}, 3^{\prime}$-butanodione-bis-dimethyl acetal using TFA provided diol $\mathbf{1 2}$ in 85\% yield, the key intermediate in the preparation of $\mathbf{7}$.

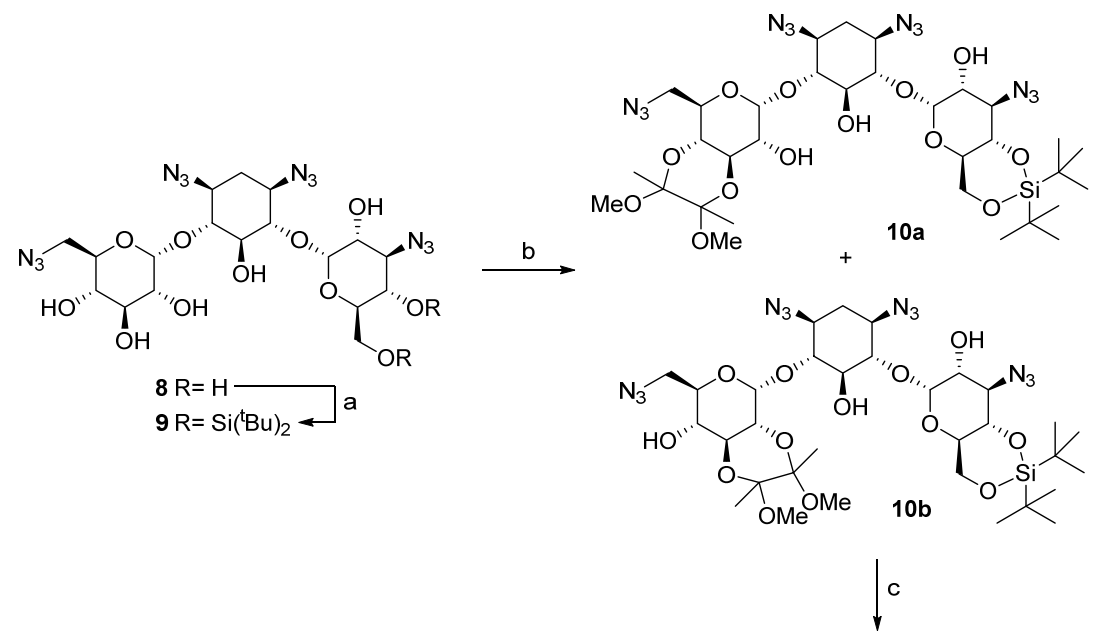

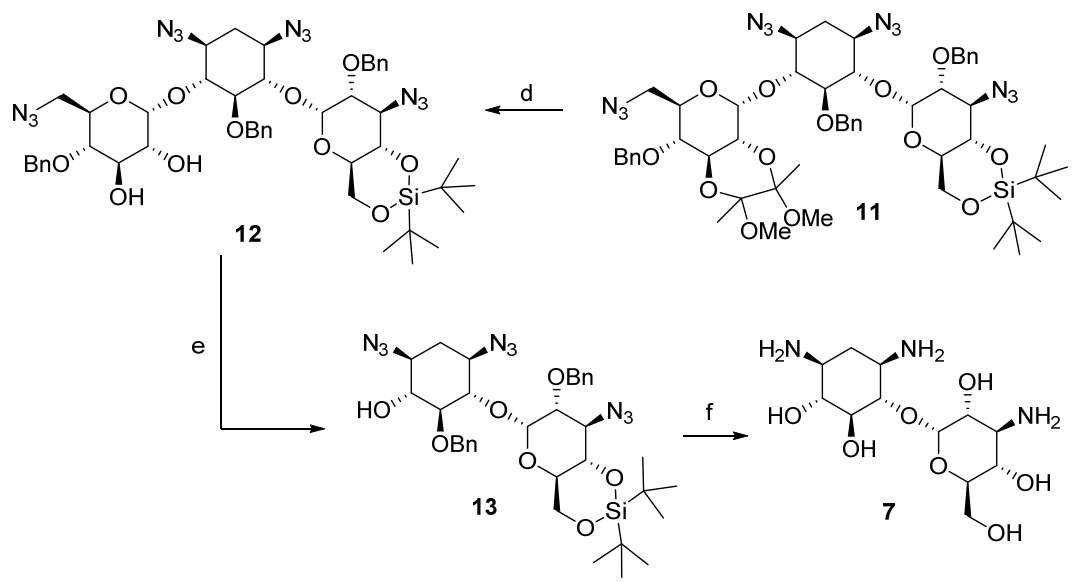

Scheme 1. Reagents and conditions: (a) $\mathrm{tBu}_{2} \mathrm{Si}(\mathrm{OTf})_{2}, \mathrm{DMAP}$, py, r.t., 24 h., 80\%; (b) 2,2,3,3-tetramethoxybutane, $\mathrm{CH}\left(\mathrm{OCH}_{3}\right)_{3}$, 2,3-butanodione, p-TosOH, $\mathrm{MeOH}$, reflux, 12 h., 77\%; (c) BnBr, TBAI, NaH, DMF, r.t., 24 h., 65\%; (d) TFA:H $\mathrm{H}_{2} \mathrm{O}$ (1:1), r.t.; 40 min.; 75\%; (e) i. $\mathrm{NaIO}_{4}, \mathrm{MeOH}, 0{ }^{\circ} \mathrm{C}$, 12 h., ii. TEA, THF, r.t., 12 h., $88 \%$ (two steps); (f) i. TBAF, THF, r.t., 24 h., ii. $\mathrm{PMe}_{3}, \mathrm{NaOH}(0.1 \mathrm{M}), \mathrm{THF}$, $55^{\circ} \mathrm{C}, 12$ h., iii. $\mathrm{H}_{2}, \mathrm{Pd}(\mathrm{OH})_{2} \cdot \mathrm{C}, \mathrm{H}_{2} \mathrm{O} / \mathrm{TFA}(1: 1)$, r.t., 12 h. $47 \%$ (three steps).

Oxidation of $\mathbf{1 2}$ was found to proceed efficiently with a moderate excess of sodium periodate in THF [25]. Treatment of the resulting dialdehyde intermediate in methanol solution with triethylamine effected the desired $\beta$-elimination to give a solid product that was assigned as the expected pseudo-disaccharide structure 13. Finally, cleavage of the silyl-acetal function in the presence of TBAF, removal of the azide groups by Staudinger reduction and subsequent catalytic hydrogenolysis gave the desired pseudo-disaccharide 7 (Supplementary Material, Figure S1).

\subsection{Antibiotic Activity and Resistance Enzyme Susceptibility of $\mathbf{7}$}

To assess the effect that ring I cleavage exhibits on the antibacterial capacity, minimum inhibitory concentration (MIC) values of the parent kanamycin A (1) and the fragments neamine (4) and pseudo-disaccharide 7, were measured against a battery of antibiotic non-resistant and resistant strains (Table 1). 
Table 1. MIC values of kanamycin A (1), neamine (4) and compound 7 against non-resistant and resistant strains.

\begin{tabular}{|c|c|c|c|c|}
\hline \multirow{2}{*}{ Entry } & \multirow{2}{*}{ Strain } & \multicolumn{3}{|c|}{ MIC ( $\left.\mu \mathrm{g} \mathrm{mL}^{-1}\right)$ Compounds } \\
\hline & & 1 & 4 & 7 \\
\hline 1 & E. coli/ATCC 2592 & 4 & 100 & 50 \\
\hline 2 & E. coli BL21 & 6 & 100 & 50 \\
\hline 3 & B. cereus/ATCC 117781 & 1.5 & 100 & 50 \\
\hline 4 & S. epidermis/ATCC 1228 & $>100$ & $>50$ & 50 \\
\hline 5 & E. coli (APH-3"IIa) & $>200$ & $>200$ & 100 \\
\hline 6 & E. coli $\left(\mathrm{ANT}-4^{\prime}\right)$ & $>200$ & $>200$ & 100 \\
\hline 7 & E. coli (AAC-6') & $>200$ & $>200$ & 100 \\
\hline
\end{tabular}

According to the obtained data, pseudo-disaccharide 7 showed an expected drop in efficacy $\left(\mathrm{MIC}=50-100 \mu \mathrm{g} \mathrm{mL}^{-1}\right)$ in comparison with the natural kanamycin A $1\left(\mathrm{MIC}=1.5-6 \mu \mathrm{gL}^{-1}\right)$. Remarkably, derivative 7 still represents an improvement over neamine (4), lowering the MIC value from $100 \mu \mathrm{g} \mathrm{mL} \mathrm{m}^{-1}$ to $50 \mu \mathrm{g} \mathrm{mL} \mathrm{g}^{-1}$. Interestingly, according to the MIC values measured for compound 7 (Table 1, entries 5-6), while a complete loss of activity for antibiotic 1 and for neamine (4) was observed, fragment 7 maintains some activity against aminoglycoside inactivation performed by $\mathrm{APH}-\left(3^{\prime}\right)$ and AAC- $\left(6^{\prime}\right)$. These results are in agreement with the relative enzymatic activity observed: for APH- $\left(3^{\prime}\right)$ and for AAC- $\left(6^{\prime}\right)$ the rate of phosphorylation/acetylation $\left(\mathrm{V}_{\text {rel }}(7) / \mathrm{V}_{\text {rel }}(\mathbf{1})\right)$ is zero, indicating that compound 7 is not inactivated by these enzymes. However, in the case of ANT( $\left.4^{\prime}\right)$, adenylation was much less effective $\left[\left(\mathrm{V}_{\text {rel }}(5) / \mathrm{V}_{\text {rel }}(\mathbf{1})=0.11\right]\right.$, whereby position 4 " of original III ring of $\mathbf{1}$ is being slowly modified [26]. This is in agreement with results previously described by our group, where we demonstrated that ANT- $\left(4^{\prime}\right)$ exhibits a remarkably low sensitivity toward the drug global shape and represents a paradigmatic example of substrate promiscuity [27].

Finally, we evaluated the capacity of kanamycin A (1), neamine (4) and pseudo-disaccharide 7 to bind the aforementioned enzymes ANT- $\left(4^{\prime}\right), \mathrm{APH}-\left(3^{\prime}\right)$ and AAC- $\left(6^{\prime}\right)$ employing thermal melting shift experiments (Table 2$)$. The change in unfolding transitions temperature $(\Delta \mathrm{Tm})$ in the presence and in the absence of the ligands provides an estimation of the ligand/protein complex stability. Surprisingly, compound 7 proved to be an appropriate ligand not only for ANT- $\left(4^{\prime}\right)$, but also for AAC- $\left(6^{\prime}\right)$ and APH- $\left(3^{\prime}\right)$ even through it is not a substrate of these latter enzymes, producing clear thermal stabilizations of all of them $\left(\Delta \mathrm{Tm}=5-7^{\circ} \mathrm{C}\right)$.

Table 2. Tm values of resistant enzymes with and without kanamycin A (1), neamine (4) and compound 7.

\begin{tabular}{ccccc}
\hline Enzyme & Blank & $\mathbf{1}$ & $\mathbf{4}$ & $\mathbf{7}$ \\
\hline ANT- $\left(4^{\prime}\right)$ & $58 \pm 0.1$ & $61.5 \pm 0.1$ & $61 \pm 0.1$ & $59 \pm 0.1$ \\
AAC- $\left(6^{\prime}\right)$ & $44 \pm 0.09$ & $49 \pm 0.1$ & $48 \pm 0.2$ & $49 \pm 0.1$ \\
APH-(3') & $49 \pm 0.09$ & $62 \pm 0.1$ & $56 \pm 0.2$ & $56 \pm 0.1$ \\
\hline
\end{tabular}

In conclusion, and considering the kinetic parameters, the estimated ligands binding affinity and the MIC values, compound 7 maintains a bactericidal activity even in resistant strains unlike neamine (4), where AAC- $\left(6^{\prime}\right)$ and APH- $\left(3^{\prime}\right)$ were shown unable to modify the substrate and ANT- $\left(4^{\prime}\right)$ only barely, while in all three cases 7 is a ligand of the enzymes. These results strongly suggest that compound 7 should be carefully considered in the design of novel antibiotics with improved activity against resistant strains and inhibitors of these aminoglycoside modifying enzymes. 


\section{Materials and Methods}

\subsection{General Procedures}

All reactions were carried out in oven-dried glassware under a positive pressure of argon unless otherwise noted. Neomycin B and Kanamycin A free bases were prepared from the corresponding monosulfate salts (purchased from Santa Cruz Biotechnology, inc. and Sigma-Aldrich, respectively) by use of Amberlite-IRA $400\left(\mathrm{OH}^{-}\right)$strongly basic ion-exchange resin. Solvents were dried in a Pure Solv system model PS-400-3-MD. Reactions were monitored by analytical thin-layer chromatography (TLC) on EM silica gel 60 F254 plates $(0.25 \mathrm{~mm})$, visualized by ultraviolet light and/or by staining with ceric ammonium molybdate, $\mathrm{H}_{2} \mathrm{SO}_{4}$ or ninhydrin. Column chromatography was performed on Silice $60(230-400 \mu \mathrm{M})$ and on Amberlite CG-50 $\left(\mathrm{NH}^{+}{ }^{+}\right)$cation exchange resin. ${ }^{1} \mathrm{H}$ NMR spectra were recorded on a Varian Inova-400 (400 MHz) and Varian UNITY $500(500 \mathrm{MHz})$ in $\mathrm{CDCl}_{3}, \mathrm{CD}_{3} \mathrm{OD}$ and $\mathrm{D}_{2} \mathrm{O}$ solutions at ambient temperature. Data were reported as follows: chemical shift on the $\delta$ scale (either using TMS or residual proton solvent as internal standard), multiplicity (br = broad, s = singlet, $\mathrm{d}=$ doublet, $\mathrm{t}=$ triplet, $\mathrm{q}=$ quartet, $\mathrm{m}=$ multiplet), coupling constant(s) in hertz, and integration. ${ }^{13} \mathrm{C}$ NMR spectra were recorded on a Varian Inova-400 (100 MHz) and Varian UNITY 500 (125 MHz). Mass spectra were recorded on an AGILENT 6520 Accurate-Mass QTOF LC/MS spectrometer using the electrospray modes (ES).

\subsection{Synthesis of 4-O-(2,6-di-Deoxy- $\alpha$-D-2,6-di-amine-glucopyranosyl)-2-deoxy-streptamine (Neamine) (4)}

Neomycin B free base $(5.0 \mathrm{~g}, 5.5 \mathrm{mmol})$ was suspended in a mixture of $\mathrm{H}_{2} \mathrm{O} / \mathrm{MeOH}(80 \mathrm{~mL}$, 1:1 $\mathrm{v} / \mathrm{v})$ and concentrated $\mathrm{HCl}(16 \mathrm{~mL})$ was added. The mixture was stirred overnight at $75{ }^{\circ} \mathrm{C}$ and then the solvent was eliminated under reduced pressure. The obtained residue was re-suspended again in a mixture of $\mathrm{H}_{2} \mathrm{O} / \mathrm{MeOH}(80 \mathrm{~mL}, 1: 1 \mathrm{v} / \mathrm{v})$ and the reaction was heated at $75^{\circ} \mathrm{C}$ for $12 \mathrm{~h}$. Finally, the solvent was partially eliminated under vacuum (until approximately $20 \mathrm{~mL}$ ), being observed the formation of a precipitate of 4 , which was finally filtrated and washed with cold $\mathrm{Et}_{2} \mathrm{O}$ to give pure neamine 4 hydrochloride $(2.3 \mathrm{~g}, 89 \%)$ as a white solid. ${ }^{1} \mathrm{H}$ NMR $\left(\mathrm{D}_{2} \mathrm{O}, 400 \mathrm{MHz}\right) \delta: 5.90(\mathrm{~d}, J=3.7$ $\mathrm{Hz}, 1 \mathrm{H}), 4.03-3.92(\mathrm{~m}, 3 \mathrm{H}), 3.68(\mathrm{t}, J=9.9 \mathrm{~Hz}, 1 \mathrm{H}), 3.59-3.24(\mathrm{~m}, 7 \mathrm{H}), 2.49(\mathrm{dt}, J=12.6,4.3 \mathrm{~Hz}, 1 \mathrm{H})$, $1.89(\mathrm{q}, J=12.6 \mathrm{~Hz}, 1 \mathrm{H}) .{ }^{13} \mathrm{C} \mathrm{NMR}\left(\mathrm{D}_{2} \mathrm{O}, 100 \mathrm{MHz}\right) \delta: 98.1,79.7,77.2,74.5,72.7,71.2,70.3,55.5,51.7$, 50.5, 42.1, 30.3. MS-API-ES (4.HCl): $323[\mathrm{M}+\mathrm{H}]^{+}$. HRMS (ESI+) calc for $\mathrm{C}_{12} \mathrm{H}_{27} \mathrm{~N}_{4} \mathrm{O}_{6}$ 323.19251, found 323.19199 .

\subsection{Synthesis of 6-O-[(3-Deoxy-3-amino)- $\alpha$-D-glucopyranosyl]-2-deoxy-streptamine (7)}

\subsubsection{Synthesis of $1,3,6^{\prime}, 3^{\prime \prime}$-Tetra-azido-kanamycin A (8)}

Kanamycin A free base (1) $(1.35 \mathrm{~g}, 2.8 \mathrm{mmol})$ and the catalyst $\mathrm{CuSO}_{4} \cdot 5 \mathrm{H}_{2} \mathrm{O}(7 \mathrm{mg}, 0.028 \mathrm{mmol})$ were dissolved in water $(8.2 \mathrm{~mL})$ and sodium hydrogencarbonate $(0.94 \mathrm{~g}, 11.2 \mathrm{mmol})$ was added. Finally, fresh triflyl azide solution (14 mL of a $2 \mathrm{M}$ solution in toluene, $28 \mathrm{mmol}$ ) [28] was added at once with vigorous stirring, followed by a dropwise addition of a mixture of $\mathrm{MeOH}$ : pyridine (1/1 v/v, $49.2 \mathrm{~mL})$. The mixture was stirred until TLC $\left(\mathrm{CH}_{2} \mathrm{Cl}_{2}: \mathrm{MeOH}, 9: 1, \mathrm{R}_{f}=0.3\right)$ showed the reaction to be complete $(18 \mathrm{~h}$.). The solvent was removed under reduced pressure. Subsequently, the residue was treated with $\mathrm{Ac}_{2} \mathrm{O} / \mathrm{Py}(1 / 2, v / v, 30 \mathrm{~mL})$ and a catalytic amount of DMAP (17 $\left.\mathrm{mg}, 0.14 \mathrm{mmol}\right)$. The mixture was stirred for $12 \mathrm{~h}$, the solvent was eliminated under vacuum and the residue was extracted with AcOEt $(3 \times 25 \mathrm{~mL})$. The combined organic layers were dried over anhydrous $\mathrm{Na}_{2} \mathrm{SO}_{4}$, concentrated and the residue was purified by column chromatography on silica gel (hexane/ethyl acetate, 1/1) to give $2^{\prime}, 3^{\prime}, 4^{\prime}, 2^{\prime \prime}, 4^{\prime \prime}, 6^{\prime \prime}$-O-hexaacetyl-1,3,6', 3"'-tetraazido-kanamycin A (1.45 g, 60\%) as a colorless foam. ${ }^{1} \mathrm{H} \mathrm{NMR}\left(500 \mathrm{MHz}, \mathrm{CDCl}_{3}\right) \delta 5.47(\mathrm{~m}, 2 \mathrm{H}), 5.33(\mathrm{~d}, J=3.7 \mathrm{~Hz}, 1 \mathrm{H}), 5.05(\mathrm{dd}, J=9.9 \mathrm{~Hz}, 1 \mathrm{H}), 4.95-4.89$ $(\mathrm{m}, 2 \mathrm{H}), 4.78(\mathrm{dd}, 1 \mathrm{H}, J=10.5,3.7 \mathrm{~Hz}), 4.33(\mathrm{ddd}, J=9.4,5.3,2.6 \mathrm{~Hz}, 1 \mathrm{H}), 4.28(\mathrm{ddd}, J=9.9,3.7 \mathrm{~Hz}, 1 \mathrm{H})$, 4.13-4.06 (m, 2H), $4.09(\mathrm{~d}, J=10.5 \mathrm{~Hz}, 1 \mathrm{H}), 3.57(\mathrm{ddd}, J=9.4,3.1 \mathrm{~Hz}, 1 \mathrm{H}), 3.50-3.44(\mathrm{~m}, 2 \mathrm{H}), 3.42-3.29$ $(\mathrm{m}, 5 \mathrm{H}), 2.28(\mathrm{ddd}, J=13.1,4.4 \mathrm{~Hz}, 1 \mathrm{H}), 2.18(\mathrm{~s}, 3 \mathrm{H}), 2.13(\mathrm{~s}, 3 \mathrm{H}), 2.08(\mathrm{~s}, 3 \mathrm{H}), 2.05(\mathrm{~s}, 6 \mathrm{H}), 2.02(\mathrm{~s}, 3 \mathrm{H})$, 
1.57 (q, $J=12.7 \mathrm{~Hz}, 1 \mathrm{H}) . ;{ }^{13} \mathrm{C}$ NMR $\left(100 \mathrm{MHz}, \mathrm{CDCl}_{3}\right) \delta 170.3,170.1,170.0,169.9,169.8,169.7,98.0$, 97.3, 85.6, 82.1, 74.0, 71.9, 71.1, 69.9, 69.2, 68.3, 68.1, 67.6, 63.0, 61.2, 60.5, 58.7, 51.5, 32.6, 20.8, 20.7, 20.6, 20.4, 20.2, 20.1. MS-API-ES: $863[\mathrm{M}+\mathrm{Na}]^{+}$. Finally, this intermediate was de-O-acetylated by treating a solution of it $(1.45 \mathrm{~g}, 1.72 \mathrm{mmol})$ with a $1 \mathrm{M}$ solution of $\mathrm{MeONa}$ in $\mathrm{MeOH}(17.2 \mathrm{~mL}, 17.2 \mathrm{mmol})$. The mixture was stirred under an Ar atomosphere for $8 \mathrm{~h}$. The reaction mixture was neutralized with Amberlite ${ }^{\circledR}$ IRA-120 $\left(\mathrm{H}^{+}\right)$to $\mathrm{pH}=5$, filtered and the resin was washed with $\mathrm{MeOH}(20 \mathrm{~mL})$. The combined filtrates were concentrated and the residue was purified by flash chromatography on silica gel using $\mathrm{CH}_{2} \mathrm{Cl}_{2} / \mathrm{MeOH},(9: 1)$ to give $8(0.91 \mathrm{~g}, 90 \%)$ as a white solid. ${ }^{1} \mathrm{H} \mathrm{NMR}\left(\mathrm{MeOD}-\mathrm{d}_{4}\right.$, $400 \mathrm{MHz}) \delta: 5.24(\mathrm{~d}, J=3.8 \mathrm{~Hz}, 1 \mathrm{H}), 5.18(\mathrm{~d}, J=3.8 \mathrm{~Hz}, 1 \mathrm{H}), 4.08-3.98(\mathrm{~m}, 2 \mathrm{H}), 3.78-3.28(\mathrm{~m}, 15 \mathrm{H}), 2.33$ $(\mathrm{dt}, J=4.2,12.6 \mathrm{~Hz}, 1 \mathrm{H}), 1.56(\mathrm{q}, J=12.4 \mathrm{~Hz}, 1 \mathrm{H}) .{ }^{13} \mathrm{C} \mathrm{NMR}\left(\mathrm{MeOD}-\mathrm{d}_{4}, 100 \mathrm{MHz}\right) \delta:$ 100.4, 98.0, 83.0, 80.2, 73.8, 72.9, 71.9, 71.5, 70.4, 70.1, 67.9, 66.4, 60.0, 58.8, 50.8, 31.5. MS-API-ES: 589 [M + H] ${ }^{+}$. HRMS (ESI+) calc for $\mathrm{C}_{18} \mathrm{H}_{29} \mathrm{~N}_{12} \mathrm{O}_{11} 589.20733$, found 589.20699.

\subsubsection{Synthesis of $4^{\prime \prime}, 6^{\prime \prime}-O-d i-t e r t-B u t y l-s i l a n e-1,3,6^{\prime}, 3^{\prime \prime}$-tetra-azido-kanamycin A (9)}

To a well-stirred solution of $8(0.91 \mathrm{~g}, 1.55 \mathrm{mmol})$ and DMAP $(0.094 \mathrm{~g}, 0.77 \mathrm{mmol})$ in pyridine $(3 \mathrm{~mL})$ at $-10^{\circ} \mathrm{C}$ was added dropwise di-tert-butylsilyl bis(trifluoromethanesulfonate) $(0.95 \mathrm{~g}, 2.17 \mathrm{mmol})$. The mixture was stirred at this temperature for $10 \mathrm{~min}$ and overnight at room temperature. Then $\mathrm{MeOH}$ $(1 \mathrm{~mL})$ was added and the mixture was concentrated. Next, a mixture of AcOEt $(100 \mathrm{~mL})$ and brine $(100 \mathrm{~mL})$ was added, the phases were separated and the aqueous phase was further extracted twice with AcOEt $(100 \mathrm{~mL})$. The combined organic phases were dried over anhydrous $\mathrm{Na}_{2} \mathrm{SO}_{4}$ and finally the solvent was removed under reduced pressure. Finally, the residue was purified by flash chromatography on silica gel using $\mathrm{CH}_{2} \mathrm{Cl}_{2} / \mathrm{MeOH}(9: 1)$ to give $9(0.9 \mathrm{~g}, 80 \%)$ as a white solid. ${ }^{1} \mathrm{H}$ NMR $\left(\mathrm{MeOD}_{\mathrm{d}}, 300 \mathrm{MHz}\right) \delta 5,21(\mathrm{~d}, J=3.5 \mathrm{~Hz}, 2 \mathrm{H}), 4.53(\mathrm{ddd}, J=5.1,9.6,9.6 \mathrm{~Hz}, 1 \mathrm{H}),, 4.16-4.00$ (m, $2 \mathrm{H}), 3.83-3.30(\mathrm{~m}, 14 \mathrm{H}), 2.40(\mathrm{ddd}, J=4.0,4.0,8.5 \mathrm{~Hz}, 1 \mathrm{H}), 1.59(\mathrm{q}, J=12.3,1 \mathrm{H}), 1.20(\mathrm{t}, J=7.0 \mathrm{~Hz}, 1 \mathrm{H})$, 1.08 (s, 9H, Si), 1.03 (s, 9H, Si). $\left.{ }^{13} \mathrm{C} \mathrm{NMR} \mathrm{(MeOD-d} 4,75 \mathrm{MHz}\right) \delta: 102.9,99.5,86.1,81.0,78.4,75.4,74.8$, 73.8, 73.4, 72.2, 71.6, 67.8, 67.6, 62.1, 60.6, 52.9, 33.3, 27.9, 27.8, 27.5, 23.4, 20.9. MS-API-ES: 751.3 [M + $\mathrm{Na}]^{+}$. HRMS (ESI+) calc for $\mathrm{C}_{26} \mathrm{H}_{44} \mathrm{~N}_{12} \mathrm{NaO}_{11} \mathrm{Si} 751.2914$, found 751.29108.

3.3.3. Synthesis of $2^{\prime}, 3^{\prime}-O-(2,3-B u t a n e d i o n e-b i s-d i m e t h y l-a c e t a l)-4^{\prime \prime}, 6 "$-O-di-tert-butyl-silane $-1,3,6^{\prime}, 3^{\prime \prime}$-tetra-azido-kanamycin A (10a) and $3^{\prime}, 4^{\prime}-O-(2,3-B u t a n e d i o n e-b i s-d i m e t h y l-a c e t a l)-4^{\prime \prime}, 6^{\prime \prime}-O$ -di-tert-butyl-silane-1,3,6', 3'"-tetra-azido-kanamycin A (10b)

To a well stirred solution of $9(0.90 \mathrm{~g}, 1.24 \mathrm{mmol})$ in $\mathrm{MeOH}$ was added 2,2,3,3-tetra-methoxy-butane $(0.44 \mathrm{~g}, 2.5 \mathrm{mmol})$, trimethyl orthoformate $(0.54 \mathrm{~mL}, 5.0 \mathrm{mmol}), 2,3$-butanedione $(0.12 \mathrm{~mL}, 1.37 \mathrm{mmol})$ and a catalytic amount of $p$ - TosOH $\cdot \mathrm{H}_{2} \mathrm{O}(31 \mathrm{mg}, 0.18 \mathrm{mmol})$. The mixture was refluxed for $18 \mathrm{~h}$ under Ar. Subsequently, after the system reaches room temperature, solid $\mathrm{NaHCO}_{3}$ was added $(\sim 0.3 \mathrm{~g})$ and the solvent was eliminated under reduced pressure. Then, a mixture of AcOEt $(100 \mathrm{~mL})$ and brine $(100 \mathrm{~mL})$ was added, the phases were separated and the aqueous phase was further extracted twice with AcOEt $(100 \mathrm{~mL})$. The combined organic phases were dried over anhydrous $\mathrm{Na}_{2} \mathrm{SO}_{4}$ and finally the solvent was eliminated under reduced pressure. The resulting residue was purified by flash chromatography on silica gel using hexane/AcOEt (6:4) to give $10 \mathrm{a}(0.4 \mathrm{~g}, 39 \%)$ as a white foam and 10b $(0.4 \mathrm{~g}, 39 \%)$ as a white solid. 10a: ${ }^{1} \mathrm{H} \mathrm{NMR}\left(\mathrm{CDCl}_{3}, 400 \mathrm{MHz}\right) \delta: 5.18(\mathrm{~d}, J=3.7 \mathrm{~Hz}, 1 \mathrm{H}), 5.09(\mathrm{~d}, J=3.8$ $\mathrm{Hz}, 1 \mathrm{H}), 4.75(\mathrm{sa}, 1 \mathrm{H}, \mathrm{H}-\mathrm{OH}), 4.26(\mathrm{ddd}, J=10.0,10.0,5.0 \mathrm{~Hz}, 1 \mathrm{H}), 4.17(\mathrm{ddd}, J=2.5,3.9,10.0 \mathrm{~Hz}, 1 \mathrm{H})$, $4.07(\mathrm{dd}, J=5.0,9.9 \mathrm{~Hz}, 1 \mathrm{H}), 3.98(\mathrm{t}, J=9.9 \mathrm{~Hz}, 1 \mathrm{H}), 3.86(\mathrm{dd}, J=3.5,10.1 \mathrm{~Hz}, 1 \mathrm{H}), 3.83-3.31(\mathrm{~m}, 12 \mathrm{H})$, $3.29(\mathrm{~s}, 3 \mathrm{H}), 3.27(\mathrm{~s}, 3 \mathrm{H}), 3.14(\mathrm{sa}, 1 \mathrm{H}, \mathrm{H}-\mathrm{OH}), 2.70(\mathrm{~d}, J=8.2 \mathrm{~Hz}, 1 \mathrm{H}), 2.43$ (ddd, J = 4.4, 4.4, 13.2 Hz, $1 \mathrm{H}), 1.59(\mathrm{q}, J=12.5 \mathrm{~Hz}), 1.34(\mathrm{~s}, 3 \mathrm{H}), 1.34(\mathrm{~s}, 3 \mathrm{H}), 1.05(\mathrm{~s}, 9 \mathrm{H}), 0.97(\mathrm{~s}, 9 \mathrm{H}) ;{ }^{13} \mathrm{C} \mathrm{NMR}\left(\mathrm{CDCl}_{3}, 100 \mathrm{MHz}\right)$ $\delta: 101.5,99.8,99.7,98.5,85.6,81.2,76.8,74.0,70.5,70.4,70.0,69.4,67.1,66.4,66.3,65.9,59.6,59.1,50.1$,

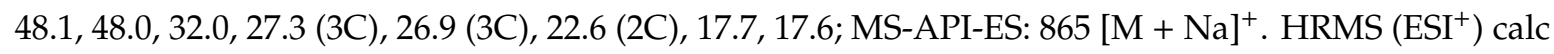
for $\mathrm{C}_{32} \mathrm{H}_{54} \mathrm{~N}_{12} \mathrm{NaO}_{13} \mathrm{Si} 865.35948$, found 865.35922. 10b: ${ }^{1} \mathrm{H} \mathrm{NMR}\left(\mathrm{CDCl}_{3}, 400 \mathrm{MHz}\right) \delta: 5.06(\mathrm{~d}, J=3.7$ $\mathrm{Hz}, 2 \mathrm{H}), 4.51(\mathrm{~d}, J=1.1 \mathrm{~Hz}), 4.20(\mathrm{ddd}, J=5.0,10.1,10.1 \mathrm{~Hz}, 1 \mathrm{H}), 4.07(\mathrm{dd}, J=4.2,5.6 \mathrm{~Hz}, 1 \mathrm{H}), 4.04-3.96$ (m, 2H), 3.88-3.72 (m, 4H), 3.69-3.29 (m, 9H), $3.28(\mathrm{~s}, 3 \mathrm{H}), 3.26(\mathrm{~s}, 3 \mathrm{H}), 2.62(\mathrm{~d}, J=8.3 \mathrm{~Hz}, 1 \mathrm{H}), 2.43$ (ddd, 
$J=3.6,3.6,8.3 \mathrm{~Hz}, 1 \mathrm{H}), 2.36(\mathrm{~d}, J=2.3 \mathrm{~Hz}, 1 \mathrm{H}), 1.56(\mathrm{q}, J=12.4 \mathrm{~Hz}, 1 \mathrm{H}), 1.34(\mathrm{~s}, 6 \mathrm{H}), 1.31(\mathrm{~s}, 3 \mathrm{H}), 1.06(\mathrm{~s}$, 9H), $1.00(\mathrm{~s}, 9 \mathrm{H}) ;{ }^{13} \mathrm{C} \mathrm{NMR}\left(\mathrm{CDCl}_{3}, 100 \mathrm{MHz}\right) \delta: 100.9,100.4,99.6,99.3,87.3,85.6,81.9,77.2,73.4,72.8$, 70.6, 68.8, 68.7, 68.1, 67.1, 66.9, 66.7, 66.4, 59.9, 48.4, 48.1, 32.2, 27.4 (3C), 26.9 (3C), 22.7 (2C), 17.7, 17.6; MS-API-ES: $865[\mathrm{M}+\mathrm{Na}]^{+}$. HRMS $\left(\mathrm{ESI}^{+}\right)$calc for $\mathrm{C}_{32} \mathrm{H}_{54} \mathrm{~N}_{12} \mathrm{NaO}_{13} \mathrm{Si}$ 865.35948, found 865.35965.

3.3.4. Synthesis of 5,2', 3"'-O-tri-Benzyl-2', $3^{\prime}-O$-(2,3-butanedione-bis-dimethyl-acetal)-4", $6^{\prime \prime}-O$ -di-tert-butyl-silane-1,3, $6^{\prime}, 3^{\prime \prime}$-tetra-azido-kanamycin A (11)

To a stirred solution of $\mathbf{1 0 a}(0.4 \mathrm{~g}, 0.38 \mathrm{mmol})$ and tetrabutylammonium iodide (51 $\mathrm{mg}, 0.14 \mathrm{mmol})$ in dry DMF $(1.9 \mathrm{~mL})$ at $0{ }^{\circ} \mathrm{C}$ was added $\mathrm{NaH}(60 \%$ oil suspension, $0.1 \mathrm{~g}, 2.85 \mathrm{mmol})$. The obtained mixture was stirred for $10 \mathrm{~min}$ at this temperature and then benzyl bromide $(0.27 \mathrm{~mL}, 2.24 \mathrm{mmol})$ was added dropwise. The reaction mixture was stirred overnight at room temperature and then $\mathrm{MeOH}(1.5 \mathrm{~mL})$ was added to quench. The solvent was eliminated under reduced pressure and the residue was diluted with brine, and extracted with $\mathrm{CH}_{2} \mathrm{Cl}_{2}(2 \times 25 \mathrm{~mL})$. The organic phases were dried over anhydrous $\mathrm{Na}_{2} \mathrm{SO}_{4}$, filtered and concentrated. Finally, the residue was purified by flash chromatography on silica gel using hexane/AcOEt (95:5) to give $\mathbf{1 1}(0.28 \mathrm{~g}, 65 \%)$ as a white solid. ${ }^{1} \mathrm{H}$ NMR $\left(\mathrm{CDCl}_{3}, 400 \mathrm{MHz}\right) \delta 7.45-7.00(\mathrm{~m}, 15 \mathrm{H}, \mathrm{Ar}), 5.46(\mathrm{~d}, J=4.1 \mathrm{~Hz}, 1 \mathrm{H}), 5.22(\mathrm{~d}, J=3.6 \mathrm{~Hz}, 1 \mathrm{H}), 5.04$ $(\mathrm{d}, J=11.2 \mathrm{~Hz}, 1 \mathrm{H}), 4.81(\mathrm{~d}, J=12.1 \mathrm{~Hz}, 1 \mathrm{H}), 4,76(\mathrm{~d}, J=11.3 \mathrm{~Hz}, 1 \mathrm{H}), 4.66(\mathrm{~d}, J=11.2 \mathrm{~Hz}, 1 \mathrm{H}), 4.63(\mathrm{~d}, J$ $=12.1 \mathrm{~Hz}, 1 \mathrm{H}), 4.36(\mathrm{dd}, J=4.8,2.4 \mathrm{~Hz}, 1 \mathrm{H}), 4.34(\mathrm{~d}, J=11.3 \mathrm{~Hz}, 1 \mathrm{H}), 4.14(\mathrm{t}, J=10.1 \mathrm{~Hz}, 1 \mathrm{H}), 3.91(\mathrm{dd}$, $J=10.0,5.0 \mathrm{~Hz}, 1 \mathrm{H}), 3.82(\mathrm{dd}, J=10.2,5.3 \mathrm{~Hz}, 1 \mathrm{H}), 3.80(\mathrm{t}, J=9.4 \mathrm{~Hz}, 1 \mathrm{H}), 3.64(\mathrm{dd}, J=10.0,2.5 \mathrm{~Hz}$, $1 \mathrm{H}), 3.61-3.56(\mathrm{~m}, 1 \mathrm{H}), 3.55-3.53(\mathrm{~m}, 1 \mathrm{H}), 3.50-3.45(\mathrm{~m}, 2 \mathrm{H}), 3.44(\mathrm{~m}, 1 \mathrm{H}), 3.38(\mathrm{dd}, J=6.7,3.8 \mathrm{~Hz}, 1 \mathrm{H})$, $3.32-3.26(\mathrm{~m}, 2 \mathrm{H}), 3.24(\mathrm{~s}, 3 \mathrm{H}), 3.25(\mathrm{~s}, 3 \mathrm{H}), 3.20-3.17(\mathrm{~m}, 2 \mathrm{H}), 3.16(\mathrm{dd}, J=10.3,3.5 \mathrm{~Hz}, 1 \mathrm{H}), 2.40-2.38$ $(\mathrm{m}, 1 \mathrm{H}), 1.65-1.51(\mathrm{~m}, 1 \mathrm{H}), 1.29(\mathrm{~s}, 6 \mathrm{H}), 1.02(\mathrm{~s}, 9 \mathrm{H}), 0.89(\mathrm{~s}, 9 \mathrm{H}) .{ }^{13} \mathrm{C} \mathrm{NMR}\left(\mathrm{CDCl}_{3}, 100 \mathrm{MHz}\right) \delta: 138.4$ (2C), 138.1, 129.2, 128.7 (2C), 128.4 (2C), 128.3 (2C), 128.1 (2C), 127.9 (2C), 127.7, 127.3, 126.4 (2C), 99.8, 99.6, 98.2, 97.4, 84.0, 81.4, 78.4, 77.1, 76.5, 74.4, 74.1, 73.9, 70.1, 69.4, 68.1, 67.6, 66.7, 64.7, 59.2, 50.6 (2C), 48.3, 48.2 (2C), 32.2, 31.7, 28.5, 27.6 (3C), 27.0 (3C), 22.8, 20.0. MS-API-ES: 1135 [M + Na] ${ }^{+}$. HRMS (ESI ${ }^{+}$) calc for $\mathrm{C}_{53} \mathrm{H}_{72} \mathrm{~N}_{12} \mathrm{NaO}_{13} \mathrm{Si} 1035.50033$, found 1035.50102.

\subsubsection{Synthesis of 5,2',3"-O-tri-Benzyl-4", $6^{\prime \prime}$-O-di-tert-butyl-silane-1,3,6', 3"'-tetra-azido-kanamycin A (12)}

To a solution of $\mathbf{1 1}(0.25 \mathrm{~g}, 0.22 \mathrm{mmol})$ in $\mathrm{CH}_{2} \mathrm{Cl}_{2}(2.3 \mathrm{~mL})$ was added a mixture of TFA: $\mathrm{H}_{2} \mathrm{O}$ $(1 \mathrm{~mL}, 10: 1 \mathrm{v} / \mathrm{v})$. The mixture was stirred at room temperature for $40 \mathrm{~min}$ at room temperature and then, a saturated aqueous solution of $\mathrm{NaHCO}_{3}$ was added and the mixture was extracted twice with AcOEt (25 mL). The combined organic phases were dried over anhydrous $\mathrm{Na}_{2} \mathrm{SO}_{4}$, filtered and the solvent was removed under reduced pressure. Finally, the residue was purified by flash chromatography on silica gel using hexane/AcOEt (7:3) to give $12(0.27 \mathrm{~g}, 85 \%)$ as a white foam. ${ }^{1} \mathrm{H} \mathrm{NMR}\left(\mathrm{CDCl}_{3}, 400\right.$ MHz) $\delta 7.44-7.17(\mathrm{~m}, 15 \mathrm{H}), 5.39(\mathrm{~d}, J=4.1 \mathrm{~Hz}, 1 \mathrm{H}), 5.34(\mathrm{~d}, J=3.4 \mathrm{~Hz}), 5.00(\mathrm{~d}, J=10.2 \mathrm{~Hz}, 1 \mathrm{H}), 4.93(\mathrm{~d}$, $J=11.2 \mathrm{~Hz}, 1 \mathrm{H}), 4.82(\mathrm{~d}, J=10.2 \mathrm{~Hz}, 1 \mathrm{H}), 4.66(\mathrm{~d}, J=11.8 \mathrm{~Hz}, 1 \mathrm{H}), 4.59(\mathrm{~d}, J=11.2 \mathrm{~Hz}, 1 \mathrm{H}), 4.20(\mathrm{ddd}, J$ $=9.9,5.3,2.4 \mathrm{~Hz}, 1 \mathrm{H}), 3.93-3.91(\mathrm{~m}, 2 \mathrm{H}), 3.89(\mathrm{~m}, 1 \mathrm{H}), 3.82(\mathrm{dd}, J=9.8,8.9 \mathrm{~Hz}, 1 \mathrm{H}), 3.69(\mathrm{t}, J=9.4 \mathrm{~Hz}$, $1 \mathrm{H}), 3.65(\mathrm{~m}, 2 \mathrm{H}), 3.60(\mathrm{~m}, 1 \mathrm{H}), 3.58(\mathrm{ddd}, J=9.4,5.6,3.2 \mathrm{~Hz}, 1 \mathrm{H}), 3.55(\mathrm{~m}, 1 \mathrm{H}), 3.49(\mathrm{~m}, 1 \mathrm{H}), 3.42(\mathrm{dd}, J$ $=13.3 \mathrm{~Hz}, 1 \mathrm{H}), 3.32(\mathrm{ddd}, J=5.7,3.0,1.3 \mathrm{~Hz}, 1 \mathrm{H}), 3.28(\mathrm{~m}, 1 \mathrm{H}), 2.24(\mathrm{dt}, J=12.5,4.0 \mathrm{~Hz}, 1 \mathrm{H}), 1.36(\mathrm{q}, J$ $=12.5 \mathrm{~Hz}, 1 \mathrm{H}), 1.02(\mathrm{~s}, 9 \mathrm{H}), 0.89(\mathrm{~s}, 9 \mathrm{H}) .{ }^{13} \mathrm{C} \mathrm{NMR}\left(\mathrm{CDCl}_{3}, 100 \mathrm{MHz}\right) \delta: 138.6,138.5,138.3,128.3(2 \mathrm{C})$, $128.2(2 \mathrm{C}), 128.1(2 \mathrm{C}), 128.0(2 \mathrm{C}), 127.9(2 \mathrm{C}), 127.8,127.5,127.2(2 \mathrm{C}), 127.1,97.8,97.5,83.9,78.7,78.6,77.0$, 76.8, 74.5, 74.1, 73.8, 73.2, 72.2, 70.9, 67.6, 66.6, 64.9, 59.8, 59.6, 51.7, 46.8, 31.9, 26.7 (3C), 26.3 (3C), 22.3, 19.5. MS-API-ES: $=999[\mathrm{M}+\mathrm{H}]^{+}$. HRMS $\left(\mathrm{ESI}^{+}\right)$calc for $\mathrm{C}_{47} \mathrm{H}_{63} \mathrm{~N}_{12} \mathrm{O}_{11} \mathrm{Si} 999.45030$, found 999.45168 .

3.3.6. Synthesis of 1,3-di-Azido-5-O-benzyl-[(3-deoxy-3-azido-2-O-Benzyl-4,6-O-di-tert-butyl-silane) - $\alpha$-D-glucopyranosyl]-2-deoxy-streptamine (13)

To a well stirred solution of $12(0.27 \mathrm{~g}, 0.27 \mathrm{mmol})$ in $\mathrm{MeOH}(8.8 \mathrm{~mL})$ at $0{ }^{\circ} \mathrm{C}$ was added $\mathrm{NaIO}_{4}$ $(0.1 \mathrm{~g}, 0.52 \mathrm{mmol})$. The resulting suspension was stirred at this temperature for $24 \mathrm{~h}$ and then the mixture was filtered through Celite ${ }^{\circledR}$, which was washed with AcOEt. The mixture was concentrated and the residue was dissolved in THF $(6.6 \mathrm{~mL})$ and treated with TEA $(110 \propto \mathrm{L}, 0.79 \mathrm{mmol})$. The reaction 
was stirred under Ar at room temperature overnight and then the solvent was eliminated under vacuum. The residue was purified by flash chromatography on silica gel using hexane/AcOEt (9:1) to give $13(0.17 \mathrm{~g}, 88 \%)$ as a white solid. ${ }^{1} \mathrm{H} \mathrm{NMR}\left(\mathrm{CDCl}_{3}, 500 \mathrm{MHz}\right) \delta: 7.44-7.28(10 \mathrm{H}, \mathrm{m}), 5.43(1 \mathrm{H}, \mathrm{d}, J$ $=3.8 \mathrm{~Hz}), 5.0(1 \mathrm{H}, \mathrm{d}, J=11.8 \mathrm{~Hz}), 4.81(1 \mathrm{H}, \mathrm{d}, J=12.0 \mathrm{~Hz}), 4.68(1 \mathrm{H}, \mathrm{d}, J=11.1 \mathrm{~Hz}), 4.10(1 \mathrm{H}, \mathrm{dd}, J=$ $5.1,10.0 \mathrm{~Hz}), 4.03(1 \mathrm{H}, \mathrm{ddd}, J=5.1,9.9,9.9), 3.88(1 \mathrm{H}, \mathrm{dd}, J=9.5,10.1 \mathrm{~Hz}), 3.80(1 \mathrm{H}, \mathrm{dd}, J=10.1,10.1$ $\mathrm{Hz}), 3.75(\mathrm{dd}, J=9.5,9.5 \mathrm{~Hz}, 1 \mathrm{H}), 3.55-3.30(5 \mathrm{H}, \mathrm{m}), 3.30(\mathrm{dd}, J=3.8,10.3 \mathrm{~Hz}, 1 \mathrm{H}), 2.22(\mathrm{~m}, 1 \mathrm{H}), 2.21(\mathrm{~d}$,

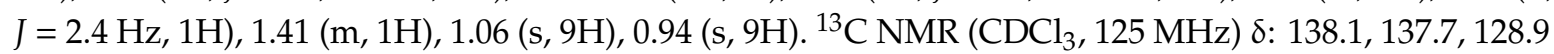
(2C), 128.5 (2C), 128.2, 127.94, 127.92 (2C), 127.6 (2C), 96.9, 83.2, 79.3, 77.0, 76.9, 76.4, 75,3, 73.4, 67.1, 66.6, 64.8, 60.4, 59.7, 31.9, 27.6 (3C), 26.9 (3C), 22.7, 19.8. MS-API-ES: 744.3 [M + Na] ${ }^{+}$. HRMS (ESI ${ }^{+}$) calc for $\mathrm{C}_{34} \mathrm{H}_{47} \mathrm{~N}_{9} \mathrm{NaO}_{7} \mathrm{Si} 744.32599$, found 744.32621 .

3.3.7. Synthesis of 6-O-[(3-Deoxy-3-amino)- $\alpha$-D-glucopyranosyl]-2-deoxy-streptamine (7)

To a solution of $13(0.17 \mathrm{~g}, 0.23 \mathrm{mmol})$ in dry THF $(5 \mathrm{~mL})$ was added dropwise TBAF (1M, THF) $(1.15 \mathrm{~mL}, 1.15 \mathrm{mmol})$. The reaction was stirred under Ar at room temperature for $24 \mathrm{~h}$ and then the mixture was concentrated under reduced pressure. The residue was dissolved in THF and an aqueous solution of $0.1 \mathrm{M} \mathrm{NaOH}(0.44 \mathrm{~mL})$ and a $1.0 \mathrm{M}$ solution of $\mathrm{PMe}_{3}$ in THF $(1.25 \mathrm{~mL})$ were sequentially added. The solution was stirred at $55^{\circ} \mathrm{C}$ overnight and then $\mathrm{MeOH}$ was added ( $\left.3 \mathrm{~mL}\right)$. The mixture was concentrated under reduced pressure and the residue was filtered through a pad of silica gel using $\mathrm{NH}_{4} \mathrm{OH} / \mathrm{BuOH} / \mathrm{EtOH} /$ toluene (4:3.5:2:1) as eluent. The obtained compound was dissolved in a mixture of $\mathrm{H}_{2} \mathrm{O} / \mathrm{TFA}(4.4 \mathrm{~mL}, 1: 1 \mathrm{v} / \mathrm{v})$ and a catalytic amount of $\mathrm{Pd}(\mathrm{OH})_{2} / \mathrm{C}(20 \%)$ was added. The reaction mixture was stirred under $\mathrm{H}_{2}$ atmosphere (balloon), and then filtered through Celite ${ }^{\circledR}$ and the filtrate was concentrated under reduced pressure. Finally, the residue was purified by flash chromatography on silica gel using $\mathrm{NH}_{4} \mathrm{OH} / \mathrm{BuOH} / \mathrm{EtOH} / \mathrm{CH}_{2} \mathrm{Cl}_{2}$ (4:3:2.5:1) followed by an ion exchange chromatography on Amberlite ${ }^{\circledR}$ CG-50 using $\mathrm{NH}_{4} \mathrm{OH}(0.5 \mathrm{M})$ to give $7(40 \mathrm{mg}, 47 \%)$ as a white foam. ${ }^{1} \mathrm{H} \mathrm{NMR}\left(\mathrm{D}_{2} \mathrm{O}, 500 \mathrm{MHz}\right) \delta: 4.91(\mathrm{~d}, J=3.9 \mathrm{~Hz}, 1 \mathrm{H}), 3.80(\mathrm{dt}, J=10.2,3.4 \mathrm{~Hz}, 1 \mathrm{H})$, 3.69-3.60 (m, 2H), $3.41(\mathrm{dd}, J=10.5,3.9 \mathrm{~Hz}, 1 \mathrm{H}), 3.34-3.19(\mathrm{~m}, 2 \mathrm{H}), 3.21-3.12(\mathrm{~m}, 2 \mathrm{H}), 2.92(\mathrm{t}, J=10.1$ $\mathrm{Hz}, 1 \mathrm{H}), 2.84(\mathrm{ddd}, J=12.1,9.7,4.1 \mathrm{~Hz}, 1 \mathrm{H}), 2.74(\mathrm{ddd}, J=12.2,9.9,4.2 \mathrm{~Hz}, 1 \mathrm{H}), 1.91(\mathrm{dt}, J=12.9,4.3$ $\mathrm{Hz}, 1 \mathrm{H}), 1.19$ (q, $J=12.4 \mathrm{~Hz}, 1 \mathrm{H}) .{ }^{13} \mathrm{C} \mathrm{NMR}\left(\mathrm{D}_{2} \mathrm{O}, 125 \mathrm{MHz}\right) \delta: 100.0,86.9,76.3,74.0,71.9,71.3,68.7$, 60.0, 54.2, 50.5, 50.3, 33.8. MS-API-ES: $324[\mathrm{M}+\mathrm{H}]^{+}$. HRMS (ESI ${ }^{+}$) calc for $\mathrm{C}_{12} \mathrm{H}_{26} \mathrm{~N}_{3} \mathrm{O}_{7} 324.17653$, found 324.17635 .

\subsection{MIC Determination}

The selected bacterial strains were grown in Mueller-Hinton broth $(1 \mathrm{~mL})$ until an optical density at $600 \mathrm{~nm}\left(\mathrm{OD}_{600}\right)$ of 0.5 units. At this time, kanamycin $\mathrm{A}(\mathbf{1})$, neamine (4) and pseudo-disaccharide 7, as free-bases, were added from stock solutions $(0.5-400 \propto \mathrm{g} / \mathrm{mL})$ prepared at different concentrations. These cultures were incubated at $37^{\circ} \mathrm{C}$ for $24 \mathrm{~h}$, after which the $\mathrm{OD}_{600}$ of each sample was recorded. Herein, we considered the MIC as the lowest concentration of aminoglycoside which produced an inhibition of the bacterial growth greater than $90 \%$. For resistant strains with overexpressed AAC- $\left(6^{\prime}\right)-\mathrm{Ib}$, $\mathrm{ANT}\left(4^{\prime}\right)$ or APH-(3') enzymes, E. coli (BL21) with the corresponding plasmids (pET-AAC $\left(6^{\prime}\right)-\mathrm{Ib}$, pET-ANT- $\left(4^{\prime}\right)$, and pET-APH- $\left.\left(3^{\prime}\right)\right)$ were induced with IPTG before adding the aminoglycosides.

\subsection{Enzymatic Activity}

\subsubsection{Enzymatic Activity of ANT-(4') from S. aureus by HPLC Assay}

To a solution of a total volume of $1 \mathrm{~mL}$ containing variable concentrations of kanamycin A (1), neamine (4) or compound $7(0.03-3 \mathrm{mM})$ in sodium phosphate buffer $(20 \mathrm{mM}, \mathrm{pH} 7.5)$ containing $\mathrm{MgCl}_{2}(5 \mathrm{mM})$ and ATP $(3 \mathrm{mM})$ was added the ANT- $\left(4^{\prime}\right)$ enzyme $(0.5 \mathrm{U})$. The formation of the final products (AMP-kanamycin, AMP-neamine or AMP-compound 7) was monitored by HPLC (Vydac 30/I, TFA PH $=3, \varnothing=1 \mathrm{~mL} \cdot \mathrm{min}^{-1}, \lambda=260 \mathrm{~nm}$ ), and confirmed by mass spectrometry of the final reaction 
mixtures. In the spectrum we observed the presence of the corresponding adenylated products. AMP-1: 814.7 $[\mathrm{M}+\mathrm{H}]^{+}$; AMP-4: $652.7[\mathrm{M}+\mathrm{H}]^{+}$; AMP-7: $653.7[\mathrm{M}+\mathrm{H}]^{+}$.

\subsubsection{Enzymatic Activity of APH-(3') from E. coli by ELISA}

A solution of a total volume of $1 \mathrm{~mL}$ containing variable concentrations of kanamycin A (1), neamine (4) or compound 7 (5 $\mu \mathrm{M}$ to $1.25 \mathrm{mM})$ in Hepes (50 mM, pH 7.7) containing $\mathrm{KCl}(40 \mathrm{mM}), \mathrm{MgCl}_{2}$ $(10 \mathrm{mM}), \mathrm{NADH}(247 \mu \mathrm{M})$, phosphoenolpyruvate $(2.5 \mathrm{mM})$, ATP $(1 \mathrm{mM})$ and pyruvate kinase/lactate dehydrogenase enzyme $(5 \mathrm{U})$ was incubated at $37^{\circ} \mathrm{C}$ for $5 \mathrm{~min}$. Subsequently, the APH-( $\left.3^{\prime}\right)$-III (10 U) was added. The phosphorylation of kanamycin A (1), neamine (4) and compound 7 was monitored by a spectrophotometric experiment $\left(\lambda=340 \mathrm{~nm}, \varepsilon=6220 \mathrm{M}^{-1} \cdot \mathrm{cm}^{-1}\right)$. Blank assays were prepared in identical conditions but in the absence of the aminoglycosides and their spectrophometric readings were subtracted from the reaction readings.

\subsubsection{Enzymatic Activity of AAC-(6') from S. aureus by ELISA}

To a solution of a total volume of $500 \propto \mathrm{L}$ containing DTP $(2 \mathrm{mM})$, acetyl-CoA $(40 \mu \mathrm{M})$, EDTA $(1 \mathrm{mM})$, and the enzyme $\left(10 \mu \mathrm{L}\right.$ at $\left.5 \mathrm{mg} \mathrm{mL}^{-1}\right)$ in Tris buffer $(\mathrm{pH}=7.6,50 \mathrm{mM})$ kanamycin $(\mathbf{1})$, neamine (4) or derivative 7 was added $(0.1 \mathrm{mM}-1 \mathrm{mM})$. Subsequently, the reaction mixtures were stirred at $37^{\circ} \mathrm{C}$ for $30 \mathrm{~min}$. During the reaction, spectrophotometric readings were taken every $30 \mathrm{~s}(\lambda=324 \mathrm{~nm})$.

\subsection{Thermal Shift Assay}

Thermal melting shift experiments were conducted on an iQ5 Real Time Detection System (Bio-Rad, Foster City, CA, USA) using the fluorescent dye SYPRO Orange [29]. In a typical experiment, a solution of SYPRO Orange $(2.8 \mathrm{mM})$ and protein (ANT- $\left(4^{\prime}\right)$, APH-(3')-III and AAC- $\left.\left.\left(6^{\prime}\right)-\mathrm{Ib}\right)\right)(4.4 \propto \mathrm{M})$ in Tris buffer $(10 \mathrm{mM}, \mathrm{pH} 8.0,0.2 \mathrm{mM} \mathrm{NaCl}, 90 \propto \mathrm{L})$ was mixed with a solution of the corresponding aminoglycoside $(\mathbf{1}, \mathbf{4}, \mathbf{7})(10 \propto \mathrm{M}, 100 \propto \mathrm{L})$. The final mixtures were heated from $25{ }^{\circ} \mathrm{C}$ to $70{ }^{\circ} \mathrm{C}$ with a heating rate of $0.5^{\circ} \mathrm{C} \mathrm{min}^{-1}$, measuring the fluorescence after each heating step with an Ex/Em $490 / 530 \mathrm{~nm}$.

Supplementary Materials: The following are available online at http://www.mdpi.com/2079-6382/8/3/109/s1. Figure S1: 1D- and 2D-NMR spectra of pseudo-disaccharide (7).

Author Contributions: S.G.Z. performed the synthesis of 7; A.B. performed antibacterial assays; A.G.S. and J.R. designed the experiments and wrote the manuscript.

Funding: This research was funded by the Spanish Ministerio de Economía y Competitividad, grant number MAT2015-65184-C2-2-R, and by CSIC, grant number iCOOPB20237.

Acknowledgments: A.G.S. thanks MINECO for a Juan de la Cierva-Incorporación 2016 contract.

Conflicts of Interest: The authors declare no conflict of interest.

\section{References}

1. Schatz, A.; Waksman, S.A. Effect of streptomycin and other antibiotic substances upon Mycobacterium tuberculosis and related organisms. Proc. Soc. Exp. Biol. Med. 1944, 57, 244-248. [CrossRef]

2. Santana, A.G.; Zárate, S.G.; Bastida, A.; Revuelta, J. Targeting RNA with Aminoglycosides: Current Improvements in their synthesis and Biological Activitiy. In Frontiers in Anti-Infective Drug Discovery; Atta-Ur-Rahman, F., Choudhray, M.I., Eds.; Bentham E-Books: Sharjah, UAE, 2015; pp. 131-209.

3. Takahashi, Y.; Igarashi, M. Destination of aminoglycoside antibiotics in the 'post-antibiotic era'. J. Antibiot. 2018, 71, 4-14. [CrossRef] [PubMed]

4. Walter, F.; Vicens, Q.; Westhof, E. Aminoglycoside-RNA interactions. Curr. Opin. Chem. Biol. 1999, 3, 694-704. [CrossRef]

5. Hermann, T. Strategies for the design of drugs targeting RNA and RNA-Protein complexes. Angew. Chem. Int. Edit. 2000, 39, 1891-1905. [CrossRef] 
6. Schroeder, R.; Waldsich, C.; Wank, H. Modulation of RNA function by aminoglycoside antibiotics. Embo. J. 2000, 19, 1-9. [CrossRef] [PubMed]

7. Sucheck, S.J.; Wong, C.H. RNA as a target for small molecules. Curr. Opin. Chem. Biol. 2000, 4, 678-686. [CrossRef]

8. Chellat, M.F.; Raguz, L.; Riedl, R. Targeting Antibiotic Resistance. Angew. Chem. Int. Edit. 2016, 55, 6600-6626. [CrossRef] [PubMed]

9. Hotta, K.; Kondo, S. Kanamycin and its derivative, arbekacin: Significance and impact. J. Antibiot. 2018, 71, 417-424. [CrossRef]

10. Fourmy, D.; Recht, M.I.; Puglisi, J.D. Binding of neomycin-class aminoglycoside antibiotics to the A-site of 16 S rRNA. J. Mol. Biol. 1998, 277, 347-362. [CrossRef]

11. Rai, R.; McAlexander, I.; Chang, C.W.T. Synthetic glycodiversification. From aminosugars to aminoglycoside antibiotics. A review. Org. Prep. Proced. Int. 2005, 37, 337-375. [CrossRef]

12. Allam, A.; Maigre, L.; de Sousa, R.A.; Dumont, E.; Vergalli, J.; Pages, J.M.; Artaud, I. New amphiphilic neamine conjugates bearing a metal binding motif active against MDR E-aerogenes Gram-negative bacteria. Eur. J. Med. Chem. 2017, 127, 748-756. [CrossRef] [PubMed]

13. Zimmermann, L.; Das, I.; Desire, J.; Sautrey, G.; Barros, R.S.V.; El Khoury, M.; Mingeot-Leclercq, M.P.; Decout, J.L. New Broad-Spectrum Antibacterial Amphiphilic Aminoglycosides Active against Resistant Bacteria: From Neamine Derivatives to Smaller Neosamine Analogues. J. Med. Chem. 2016, 59, 9350-9369. [CrossRef] [PubMed]

14. Garneau-Tsodikova, S.; Labby, K.J. Mechanisms of resistance to aminoglycoside antibiotics: Overview and perspectives. Med. Chem. Comm. 2016, 7, 11-27. [CrossRef] [PubMed]

15. Zarate, S.G.; Claure, M.L.D.; Benito-Arenas, R.; Revuelta, J.; Santana, A.G.; Bastida, A. Overcoming Aminoglycoside Enzymatic Resistance: Design of Novel Antibiotics and Inhibitors. Molecules 2018, 23, 18. [CrossRef] [PubMed]

16. Chandrika, N.T.; Garneau-Tsodikova, S. Comprehensive review of chemical strategies for the preparation of new aminoglycosides and their biological activities. Chem. Soc. Rev. 2018, 47, 1189-1249. [CrossRef] [PubMed]

17. Jimenez-Moreno, E.; Gomez-Pinto, I.; Corzana, F.; Santana, A.G.; Revuelta, J.; Bastida, A.; Jimenez-Barbero, J.; Gonzalez, C.; Asensio, J.L. Chemical Interrogation of Drug/RNA Complexes: From Chemical Reactivity to Drug Design. Angew. Chem. Int. Edit. 2013, 52, 3148-3151. [CrossRef] [PubMed]

18. Santana, A.G.; Zárate, S.G.; Asensio, J.L.; Revuelta, J.; Bastida, A. Selective modification of the 3"-amino group of kanamycin prevents significant loss of activity in resistant bacterial strains. Org. Biomol. Chem. 2016, 14, 516-525. [CrossRef] [PubMed]

19. Ramirez, M.S.; Tolmasky, M.E. Amikacin: Uses, Resistance, and Prospects for Inhibition. Molecules 2017, $22,23$. [CrossRef] [PubMed]

20. Matsushita, T.; Sati, G.C.; Kondasinghe, N.; Pirrone, M.G.; Kato, T.; Waduge, P.; Kumar, H.S.; Sanchon, A.C.; Dobosz-Bartoszek, M.; Shcherbakov, D.; et al. Design, Multigram Synthesis, and in Vitro and in Vivo Evaluation of Propylamycin: A Semisynthetic 4,5-Deoxystreptamine Class Aminoglycoside for the Treatment of Drug-Resistant Enterobacteriaceae and Other Gram-Negative Pathogens. J. Am. Chem. Soc. 2019, 141, 5051-5061. [CrossRef] [PubMed]

21. Santana, A.G.; Bastida, A.; del Campo, T.M.; Asensio, J.L.; Revuelta, J. An Efficient and General Route to the Synthesis of Novel Aminoglycosides for RNA Binding. Synlett 2011, 219-222. [CrossRef]

22. Yu, M.; Pagenkopf, B.L. The regioselective mono-deprotection of 1,3-dioxa-2,2-(di-tert-butyl)-2 -silacyclohexanes with BF3 center dot SMe2. J. Org. Chem. 2002, 67, 4553-4558. [CrossRef] [PubMed]

23. Yan, R.B.; Yuan, M.; Wu, Y.F.; You, X.F.; Ye, X.S. Rational design and synthesis of potent aminoglycoside antibiotics against resistant bacterial strains. Bioorg. Med. Chem. 2011, 19, 30-40. [CrossRef] [PubMed]

24. Montchamp, J.L.; Tian, F.; Hart, M.E.; Frost, J.W. Butane 2,3-bisacetal protection of vicinal diequatorial diols. J. Org. Chem. 1996, 61, 3897-3899. [CrossRef] [PubMed]

25. van den Broek, S.; Gruijters, B.W.T.; Rutjes, F.; van Delft, F.L.; Blaauw, R.H. A short and scalable route to orthogonally O-protected 2-deoxystreptamine. J. Org. Chem. 2007, 72, 3577-3580. [CrossRef] [PubMed]

26. Corzana, F.; Cuesta, I.; Freire, F.; Revuelta, J.; Torrado, M.; Bastida, A.; Jiménez-Barbero, J.; Asensio, J.L. The Pattern of Distribution of Amino Groups Modulates the Structure and Dynamics of Natural Aminoglycosides: Implications for RNA Recognition. J. Am. Chem. Soc. 2007, 129, 2849-2865. [CrossRef] [PubMed] 
27. Matesanz, R.; Diaz, J.F.; Corzana, F.; Santana, A.G.; Bastida, A.; Asensio, J.L. Multiple keys for a single lock: The unusual structural plasticity of the nucleotidyltransferase $\left(4^{\prime}\right)$ /kanamycin complex. Chem. A Eur. J. 2012, 18, 2875-2889. [CrossRef] [PubMed]

28. Titz, A.; Radic, Z.; Schwardt, O.; Ernst, B. A safe and convenient method for the preparation of triflyl azide, and its use in diazo transfer reactions to primary amines. Tetrahedron Lett. 2006, 47, 2383-2385. [CrossRef]

29. Lo, M.C.; Aulabaugh, A.; Jin, G.; Cowling, R.; Bard, J.; Malamas, M.; Ellestad, G. Evaluation of fluorescence-based thermal shift assays for hit identification in drug discovery. Anal. Biochem. 2004, 332, 153-159. [CrossRef]

(C) 2019 by the authors. Licensee MDPI, Basel, Switzerland. This article is an open access article distributed under the terms and conditions of the Creative Commons Attribution (CC BY) license (http://creativecommons.org/licenses/by/4.0/). 